\title{
Widely tunable III-V/silicon lasers for spectroscopy in the short-wave infrared
}

\author{
Ruijun Wang, Bahawal Haq, Stephan Sprengel, Aditya Malik, Anton Vasiliev, Gerhard Boehm, Ieva \\ Šimonyte, Augustinas Vizbaras, Kristijonas Vizbaras, Joris Van Campenhout, Roel Baets, Markus- \\ Christian Amann, and Gunther Roelkens
}

(Invited Paper)

\begin{abstract}
Silicon photonics can provide ultra-compact and high-performance building blocks for integrated laser sources, such as micro-ring resonators, beam combiners and gratings. Integrating III-V gain material with silicon photonic integrated circuits enables the realization of advanced laser sources and fully integrated photonics systems for optical communication and sensing applications. The availability of III-V/silicon laser sources operating in the 2-2.5 $\mu \mathrm{m}$ short-wave infrared (SWIR) wavelength range is very valuable for spectroscopic sensing since many important industrial gases and blood glucose have absorption bands in this wavelength range. In this paper, first we present our latest results on heterogeneously integrated III-V-on-silicon distributed feedback (DFB) laser arrays. A III-V-on-silicon DFB laser array covering the 2.27-2.39 $\mu \mathrm{m}$ wavelength range with $6 \mathrm{~nm}$ wavelength spacing is reported. This DFB laser array is employed as the light source for tunable diode laser absorption spectroscopy of different gases. A four-channel DFB laser array integrated with a beam combiner is used to perform spectroscopic sensing over a $7 \mathrm{~nm}$ spectral range without mode hopping at room temperature. Finally, we present our recent advances in widely tunable Vernier lasers based on heterogeneous integration and butt-coupling of the gain section. Continuous tuning near the absorption lines by thermally adjusting the laser cavity length enable highresolution TDLAS measurements together with wide wavelength coverage.
\end{abstract}

Index Terms - Semiconductor lasers, laser array, laser tuning, silicon photonics, mid-infrared

This work was supported by FP7-ERC-PoC-FireSpec and the INTERREG Safeside project.

R.Wang was with Photonics Research Group, Ghent University-imec, Center for Nano- and Biophotonics (NB-Photonics), Ghent University, B-9052 Ghent, Belgium. He is now with Institute for Quantum Electronics, ETH Zurich, 8093 Zürich, Switzerland (e-mail: Ruiwang @ phys.ethz.ch).

B. Haq, A. Vasiliev, R. Baets, G. Roelkens are with Photonics Research Group, Ghent University-imec, Center for Nano- and Biophotonics (NBPhotonics), Ghent University, B-9052 Ghent, Belgium (email: Bahawal.Haq@ugent.be, Anton.Vasiliev@ugent.be, Roel.Baets@UGent.be, Gunther.Roelkens@UGent.be).

A. Malik was with Photonics Research Group, Ghent University-imec, Center for Nano- and Biophotonics (NB-Photonics), Ghent University, B-9052

\section{INTRODUCTION}

$\mathrm{T}$ he development of silicon photonics in recent years has enabled low-cost and high-speed integrated optical transceivers used in short-distance data communication and long-haul optical transmission [1]. Integrating III-V materials or prefabricated III-V gain chips with silicon photonic integrated circuits (ICs) provides a practical solution to implement laser sources for silicon photonics applications [2][5]. This III-V/silicon hybrid approach also can be used to make advanced laser sources for optical communication and sensing applications since the silicon photonics platform can provide ultra-compact and high-performance photonic components, such as low-loss spiral waveguides, high-Q micro-ring resonators (MRRs) [6], low-loss on-chip beam combiners [7], and widely tunable filters [8]. For example, Z. Wang et al. demonstrated a passively mode-locked laser operating at 1.6 $\mu \mathrm{m}$ wavelength with a record-low repetition rate of $1 \mathrm{GHz}$ by heterogeneously integrating a III-V-on-silicon semiconductor optical amplifier (SOA) with a $3.7 \mathrm{~cm}$ long silicon-on-insulator (SOI) spiral waveguide (propagation loss $\sim 0.7 \mathrm{~dB} / \mathrm{cm}$ ) [9]. T. Kita et al. realized a III-V/silicon hybrid laser with a very wide wavelength tuning range that can cover the C-band (1530$1565 \mathrm{~nm})$ and L-band (1565-1625nm) of the optical communications window by using two silicon MRRs and an asymmetric Mach-Zehnder interferometer as the wavelength tuning filter [10]. Besides, the integration of III-V/silicon lasers with silicon photonic ICs enables fully integrated spectroscopic sensors for applications such as gas sensing [11] and biosensing [12]. In order to realize on-chip silicon photonic spectroscopic sensors, many efforts have been devoted to develop silicon waveguide-based components to probe the

Ghent, Belgium. He is now with the Department of Electrical and Computer Engineering, University of California Santa Barbara, Santa Barbara, CA 93106 USA (email: amalik@ece.ucsb.edu).

S. Sprengel, G. Boehm, M.-C. Amann are with Walter Schottky Institut, Technische Universität München, Am Coulombwall 4, 85748 Garching, Germany (e-mail: $\quad \underline{\text { Stephan.Sprengel@wsi.tum.de, }}$ Gerhard.Boehm@wsi.tum.de, mcamann@wsi.tum.de).

I. Šimonyte, A. Vizbaras, K. Vizbaras are with Brolis Semiconductors UAB, Moletu pl. 73, LT-14259, Vilnius, Lithuania (e-mail: ieva.simonyte@brolissemicon.com, augustinas.vizbaras@brolis-semicon.com, kristijonas.vizbaras@brolis-semicon.com).

J. V. Campenhout is with imec, Kapeldreef 75, 3001 Leuven, Belgium (email: joris.vancampenhout@imec.be). 
analyte [13]-[15]. However, in these on-chip silicon photonic sensors, the light from an external laser source is coupled to the chip for the absorption spectroscopy measurement, instead of using an integrated light source [11]-[15]. In order to realize a compact spectroscopic sensor, a chip-scale laser source should be integrated with the probe components. Therefore, realizing a III-V/silicon laser source is also a critical step towards on-chip silicon photonic spectroscopic sensors.

Tunable semiconductor lasers operating in the 2-2.5 $\mu \mathrm{m}$ wavelength range are very relevant for trace gas sensing since many important industrial gases (e.g., $\mathrm{CO}_{2}, \mathrm{CO}, \mathrm{CH}_{4}, \mathrm{NH}_{3}$, $\mathrm{C}_{2} \mathrm{H}_{2}$ ) have strong absorption lines in this spectral region [16]. Compared with the near infrared region, the stronger absorption cross section of the molecules enable optical gas sensors to operate in this wavelength range with higher sensitivity. Although the mid-infrared spectral region $(>2.5 \mu \mathrm{m})$ offers even stronger absorption, in the $2-2.5 \mu \mathrm{m}$ wavelength range the cheaper photonic components and low-noise photodetectors enable low-cost and miniaturized optical sensors without e.g. an extra cooling system. Among different semiconductor lasers, InP-based and GaSb-based distributed feedback (DFB) lasers and vertical cavity surface emitting lasers (VCSELs) have shown very good performance in the $2-2.5 \mu \mathrm{m}$ wavelength range [17]-[20]. However, the tuning range of a single DFB laser and VCSEL is limited around 3-5 nm. The development of widely tunable InP-based and GaSb laser sources operating in this spectral region would allow to simultaneously detect different gases. It is also very valuable for bio-sensing considering the broad absorption features of bio-molecules. For example, blood glucose has a strong combination absorption band in the 2-2.3 $\mu \mathrm{m}$ wavelength range [21]. In this wavelength range, GaSb-based gain chips coupled to a diffraction grating used for wavelength selection have shown wide tunability [22]. However, the bulky optic system and mechanical controller used in these widely tunable lasers make it less suitable for portable, low-cost optical sensing.

For the 2-2.5 $\mu \mathrm{m}$ wavelength range, semiconductor lasers based on InP-based type-I, type-II and GaSb-based type-I heterostructures have shown high performance [17]-[20]. Among these material systems, laser diodes based on the GaSbbased type-I quantum wells exhibit the best performance and can lase above $3 \mu \mathrm{m}$ wavelength [23]. However, the heterogeneous integration processes of GaSb-based materials are not as well-established as for InP-based materials, which results in a low process yield and poor device performance so far [24]. Heterogeneously integrated InP-type-I Fabry-Perot lasers on silicon operating at $2.0 \mu \mathrm{m}$ wavelength have been demonstrated [25]. However, the emission wavelength of InPbased type-I quantum well lasers is limited to around $2.3 \mu \mathrm{m}$ [26]. In recent years, InP-based type-II quantum well laser diodes with emission wavelength up to $2.7 \mu \mathrm{m}$ wavelength have been realized by employing "W"-shaped $\mathrm{InGaAs} / \mathrm{GaAsSb}$ quantum wells as the active region [27]. In this paper, we present three different types of chip-scale widely tunable lasers based on the heterogeneous integration of InP-based type-II materials on silicon or by butt-coupling a prefabricated a $\mathrm{GaSb}$ gain chip with silicon photonic ICs. The paper is organized as follows. Section II introduces the heterogeneous integration process of InP-based type-II materials and the design of the optical coupling between the III-V waveguide and silicon waveguide. Section III discusses our recent results on InP-based type-II DFB laser arrays on silicon and their application in gas sensing. Section IV focuses on heterogeneously integrated widely tunable Vernier lasers, while Section V is devoted to the widely tunable $\mathrm{GaSb} / \mathrm{silicon}$ external cavity laser. Finally, the paper is concluded in Section VI.

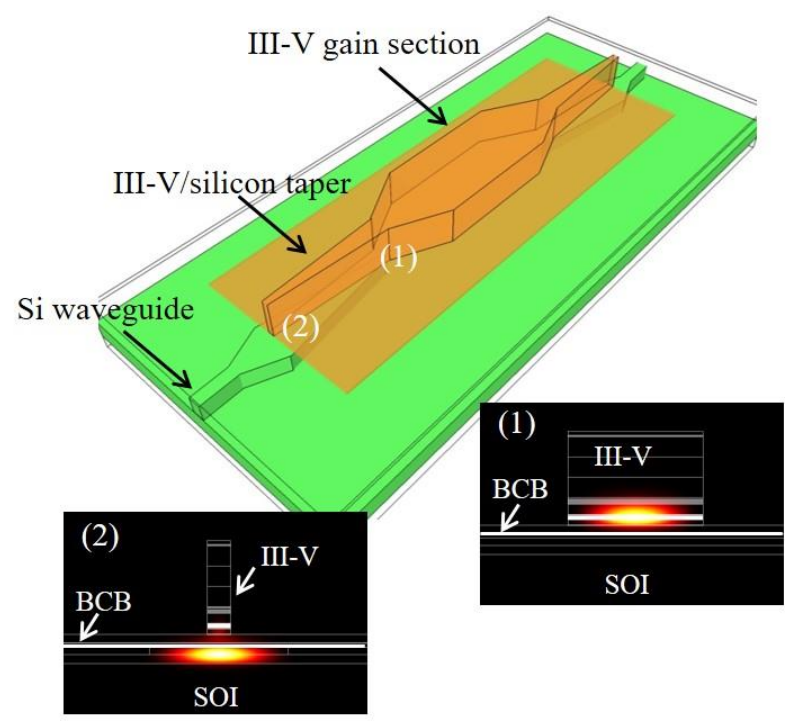

Fig.1. Schematic of the III-V-on-silicon semiconductor optical amplifier. The mode intensity distribution in the III-V/silicon hybrid waveguide at two positions is shown as an inset.

\section{HETEROGENEOUSLY INTEGRATED III-V-ON-SILICON LASERS}

A heterogeneously integrated InP-based type-II quantum well laser consists of a III-V-on-silicon semiconductor optical amplifier (SOA) and silicon waveguide-based feedback circuit. Figure 1 shows the schematic of the III-V-on-silicon SOA. The SOA is adhesively bonded on a silicon rib waveguide with an etch depth of $180 \mathrm{~nm}$ in a $400 \mathrm{~nm}$ silicon device layer and consists of a gain section in the center and two III-V/silicon spot size converters (SSCs) on both sides. In the gain section, the optical mode is strongly confined in the III-V waveguide to ensure a high modal gain. The III-V epitaxial layer stack consists of a $200 \mathrm{~nm}$ thick $n$-InP contact layer, an active region sandwiched between a $130 \mathrm{~nm}$ thick GaAsSb and a $250 \mathrm{~nm}$ thick AlGaAsSb separate confinement heterostructure layer, a $1.5 \mu \mathrm{m}$ thick $p$-InP cladding layer and a $100 \mathrm{~nm}$ thick $p+-$ InGaAs contact layer. The active region contains six periods of a "W"-shaped quantum well structure, each separated by a $9 \mathrm{~nm}$ tensile strained $\mathrm{GaAs}_{0.58} \mathrm{Sb}_{0.42}$ layer. Every quantum well structure consists of a $2.9 \mathrm{~nm}$ thick $\mathrm{GaAs}_{0.33} \mathrm{Sb}_{0.67}$ layer surrounded by two $2.6 \mathrm{~nm}$ thick $\mathrm{In}_{0.68} \mathrm{Ga}_{0.32}$ As layers. The calculated confinement factor of the TE polarized fundamental mode in the quantum wells is around $10 \%$. An efficient light coupling between the silicon waveguide and III-V waveguide is achieved by the III-V/silicon SSCs. The SSCs have two tapered section as shown in Fig.1. In the first section, the III-V 
waveguide is linearly tapered from $5 \mu \mathrm{m}$ to $1.2 \mu \mathrm{m}$ over a length of $50 \mu \mathrm{m}$. In the second section, the III-V waveguide is linearly tapered to a very narrow tip where the silicon waveguide is tapered from $0.2 \mu \mathrm{m}$ to $3 \mu \mathrm{m}$. The second section is an adiabatic inverted taper coupler, where the optical mode is gradually transferred from the III-V waveguide to silicon waveguide (and vice versa) as shown in Fig.1. The simulated coupling efficiency of the III-V/silicon SSC is around $90 \%$ when the III$\mathrm{V}$ taper tip is $0.5 \mu \mathrm{m}$ wide. Detailed information on the design of the III-V/silicon SSC can found in Ref. [28].



(a) Substrate removal

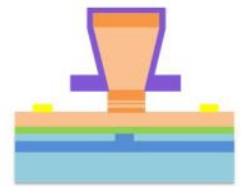

(d) N-type contact



(g) P-type contact
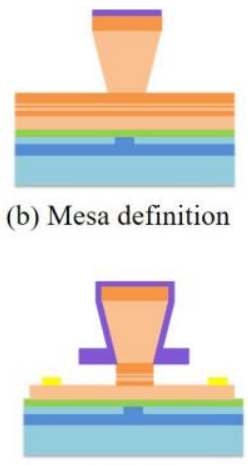

(e) Device isolation

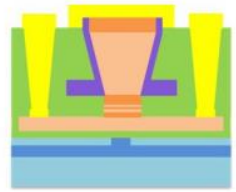

(h) Probe pad (b) Mesa definition

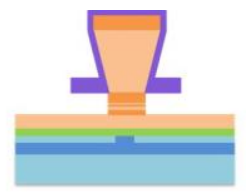

(c) Active region etching

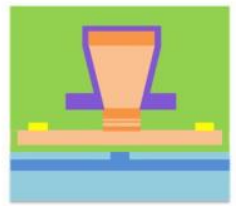

(f) Passivation

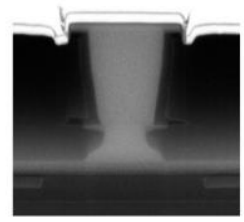

(i) Fabricated device
Fig.2. Process flow for the fabrication of III-V-on-silicon lasers.

The fabrication process of heterogeneously integrated InPbased type-II quantum well lasers can be divided in two parts: firstly the silicon waveguide circuits are processed in a CMOS pilot line on $200 \mathrm{~mm}$ SOI wafers, then the laser sources are fabricated in a III-V-on-silicon device platform developed for optical communication and sensing applications. In the CMOS pilot line, the waveguides are etched $180 \mathrm{~nm}$ deep in the 400 $\mathrm{nm}$ thick silicon device layer. To achieve a high-yield and uniform bonding, the silicon wafer is planarized by $\mathrm{SiO}_{2}$ deposition followed by a chemical mechanical polishing down to the silicon device layer. Then the III-V epitaxial layer is adhesively bonded to the silicon waveguide circuits by a $50 \mathrm{~nm}$ thick divinylsiloxane-bis-benzocyclobutene (DVS-BCB) bonding layer [29]. The following process steps are shown in Fig. 2. After bonding, the InP substrate is removed using $\mathrm{HCl}$ wet etching (Fig. 2(a)). Then the integrated lasers are processed on the III-V-on-silicon membrane. Firstly, a $200 \mathrm{~nm} \mathrm{SiN}$ layer is deposited on the sample as a hard mask. Then the III-V waveguide is defined using $320 \mathrm{~nm}$ UV contact lithography. After dry etching of the $\mathrm{SiN}_{\mathrm{x}}$ hard mask and the $p+-\mathrm{InGaAs}$ contact layer, the $1.5 \mu \mathrm{m}$ thick $p$-InP cladding layer is etched using a 1:1 $\mathrm{HCl}: \mathrm{H}_{2} \mathrm{O}$ solution (Fig. 2(b)). This anisotropic wet etching creates a "V"-shaped undercut, which ensures the IIIV/silicon SSC have a very narrow taper tip, leading to an efficient coupling between the III-V waveguide and silicon waveguide. Afterwards, a second $\mathrm{SiN}_{\mathrm{x}}$ hard mask is deposited on the sample to protect the III-V taper tip in the following wet etching. Then the active region is etched in a 1:1:20:70 $\mathrm{H}_{3} \mathrm{PO}_{4}: \mathrm{H}_{2} \mathrm{O}_{2}$ :Citric Acid: $\mathrm{H}_{2} \mathrm{O}$ solution using the $n$-InP layer as the etch stop layer (Fig. 2(c)). Afterwards, Ni/Ge/Au is deposited on the $n$-InP layer (Fig. 2(d)). After metallization and lift-off, the $n$-InP is etched by $1: 1 \mathrm{HCl}: \mathrm{H}_{2} \mathrm{O}$ to isolate different devices (Fig. 2(e)). Then a $\sim 3.5 \mu \mathrm{m}$ thick DVS-BCB layer is spin-coated on the sample to passivate the devices (Fig. 2(f)). After curing, the DVS-BCB layer is etched back to the $p+-$ InGaAs layer to expose this contact layer. Subsequently, Ti/Au is deposited on the sample as $p$-contact (Fig. 2(g)) and probe pad (Fig. 2(h)). A scanning electron microscope (SEM) image of the fabricated III-V-on-silicon lasers is shown in Fig. 2(i). This fabrication process is the same as that of the III- $\mathrm{V}$-onsilicon photodetectors operating in the $2-2.5 \mu \mathrm{m}$ wavelength range [30], thereby fully integrated spectroscopic sensors can be realized based a single epitaxial layer stack and process flow.

\section{HeterogeneOUSLY INTEGRATED 2.3 UM III-V-ON- SILICON DFB LASER ARRAY}

\section{A. Single III-V-on-silicon DFB laser}

In a heterogeneously integrated InP-based type-II DFB laser a first-order DFB grating is implemented underneath the III-Von-silicon SOA as schematically shown in Fig. 3. In the device, the tail of the optical mode interacts with the DFB grating, which selects the emission wavelength of the laser. In order to have stable single mode lasing, a quarter-wave shifted grating structure is used to break the modal degeneracy. The coupling coefficient $\kappa$ of this DFB grating is calculated to be $80 \mathrm{~cm}^{-1}$. Since the gain section length of the DFB lasers shown in this paper is $700 \mu \mathrm{m}$, the normalized coupling coefficient $\kappa \mathrm{L}$ of these DFB lasers is around 5.6.

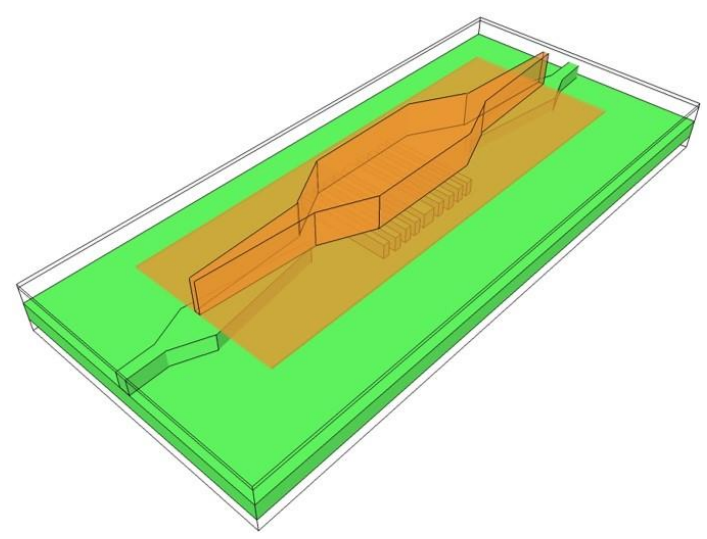

Fig.3. Schematic of the heterogeneously integrated III-V-on-silicon DFB laser.

The integrated lasers are mounted on a temperaturecontrolled stage during measurements. The light in the silicon waveguide is coupled to a standard single-mode fiber (SMF-28) via integrated chip-to-fiber couplers. To determine the waveguide-couple optical output power of the DFB laser, the 
fiber-to-chip coupler loss is measured on reference structures on the same wafer. An optical spectrum analyzer (OSA, Yokogawa AQ6375) is used to study the optical output power and emission spectra of the lasers. Figure 4 shows the continuous wave $(\mathrm{CW})$ on-chip output power-current (L-I) curve of a heterogeneously integrated InP-based type-II DFB laser with a silicon DFB grating pitch of $347 \mathrm{~nm}$. In CW regime, the laser can operate till about $25{ }^{\circ} \mathrm{C}$. The maximum on-chip output is $1.3 \mathrm{~mW}$ at $5{ }^{\circ} \mathrm{C}$ and reduces to $0.38 \mathrm{~mW}$ at $20^{\circ} \mathrm{C}$, while the threshold current increases from $52 \mathrm{~mA}$ to $76 \mathrm{~mA}$. The performance of this III-V-on-silicon laser is comparable to state-of-the-art InP-based type-II quantum well lasers on InP substate [27], [31]. Further improvement can be realized by optimizing the III-V epitaxial layer stack, especially the current injection efficiency. A fiber-coupled lasing spectrum of the device for a bias current $150 \mathrm{~mA}$ at $10{ }^{\circ} \mathrm{C}$ is shown in Fig. 5 . The dominant mode is located at $2318.5 \mathrm{~nm}$. Single mode emission with a side mode suppression ratio (SMSR) of $50 \mathrm{~dB}$ is achieved.

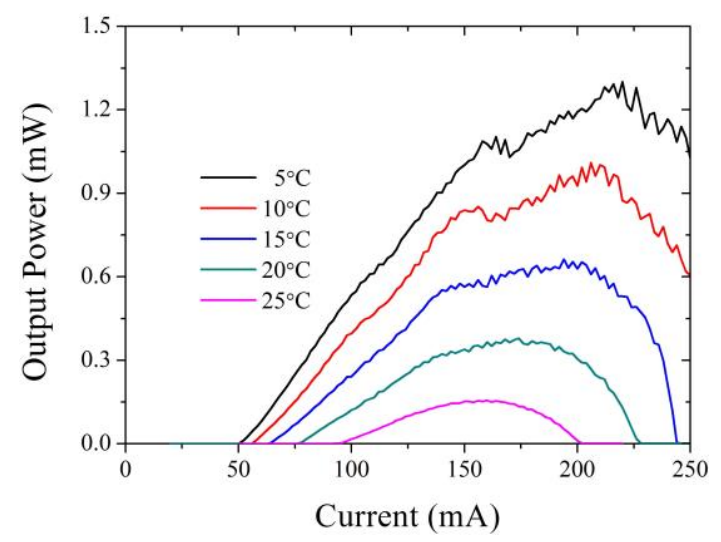

Fig. 4. CW light-current (L-I) curve of the III-V-on-silicon DFB laser with grating pitch of $347 \mathrm{~nm}$.

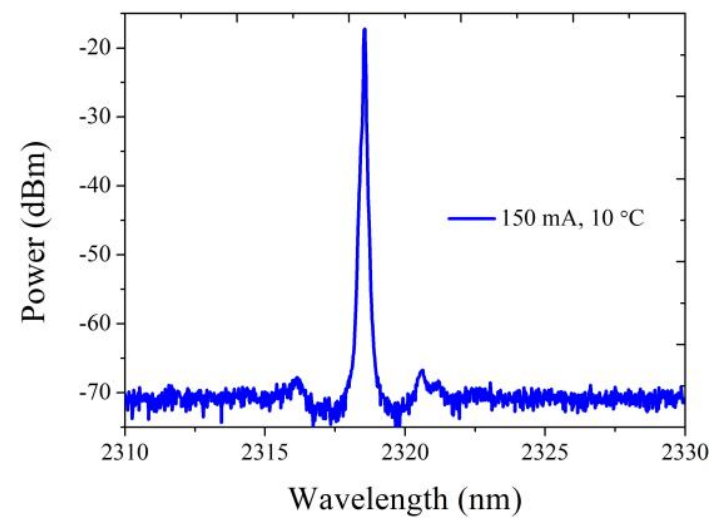

Fig. 5. Fiber-coupled laser spectrum of the III-V-on-silicon laser with DFB grating pitch of $347 \mathrm{~nm}$.

High-performance tunable diode laser absorption spectroscopy (TDLAS) requires laser sources with stable and mode-hop-free tuning. The spectral map of the DFB laser with $347 \mathrm{~nm}$ grating pitch as a function of the bias current at $5{ }^{\circ} \mathrm{C}$ and $20^{\circ} \mathrm{C}$ is shown in Fig. 6 . In both maps, the emission spectra are single mode with a very high SMSR of more than $40 \mathrm{~dB}$ throughout the current range. The lasing wavelength linearly changes with the bias current. The device exhibits more than 4 $\mathrm{nm}$ and $2.5 \mathrm{~nm}$ mode-hop-free tuning at $5{ }^{\circ} \mathrm{C}$ and $20{ }^{\circ} \mathrm{C}$, respectively. The current-tuning coefficient is around 0.02 $\mathrm{nm} / \mathrm{mA}$ at $5{ }^{\circ} \mathrm{C}$ and $0.018 \mathrm{~nm} / \mathrm{mA} 20{ }^{\circ} \mathrm{C}$. A single DFB laser has more than $6 \mathrm{~nm}$ current-tuning range when varying the chip temperature between $5{ }^{\circ} \mathrm{C}$ to $25{ }^{\circ} \mathrm{C}$. Therefore, a broad wavelength coverage III-V-on-silicon DFB laser array with wavelength spacing around $6 \mathrm{~nm}$ can be used to detect any absorption features of molecules in this spectral range. Compared with our previously demonstrated heterogeneously integrated InP-based type-II DFB laser [32]-[33], the device shown here can operate in $\mathrm{CW}$ at room temperature and above without mode-hopping.

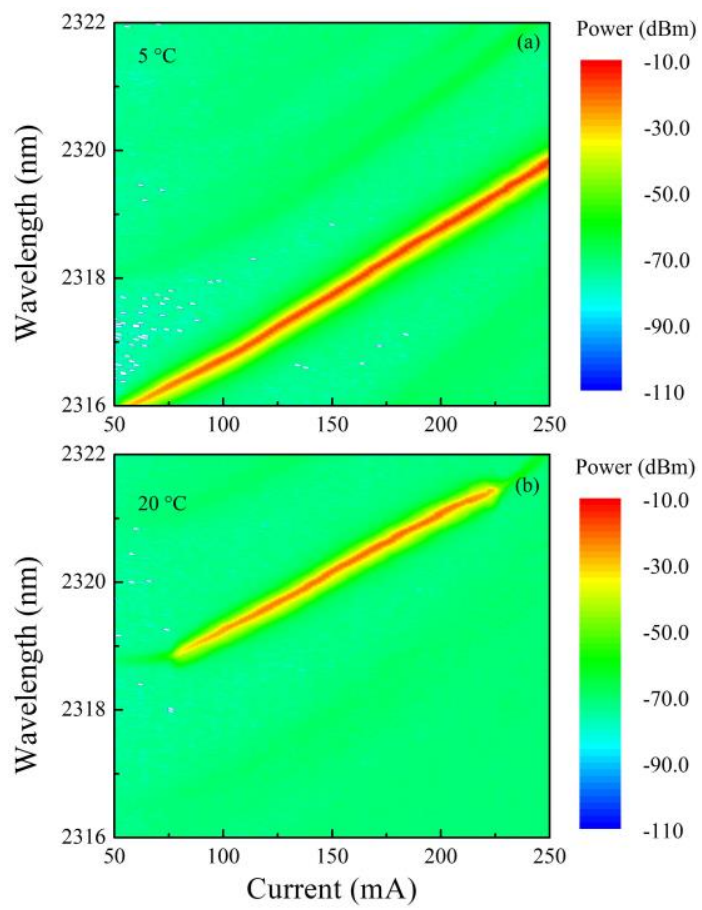

Fig. 6. Spectral map of fiber-coupled emission from the III-V-on-silicon DFB laser with grating pitch of $347 \mathrm{~nm}$ at $5{ }^{\circ} \mathrm{C}$ and $20^{\circ} \mathrm{C}$.

\section{B. III-V-on-silicon DFB Laser Array}

We have demonstrated III-V-on-silicon DFB laser arrays with wavelength spacing of $30 \mathrm{~nm}$ at $2.35 \mu \mathrm{m}$ wavelength range [33]. In order to achieve complete spectral coverage, in this paper we report a heterogeneously integrated InP-based type-II DFB laser array with a wavelength spacing of $6 \mathrm{~nm}$ (combined with the wavelength tuning discussed above). Here we take advantage of the state-of-the-art silicon photonics pilot line to fabricate silicon grating arrays with a pitch increment of $1 \mathrm{~nm}$. Figure 7 shows the normalized lasing spectra of a III-V-onsilicon DFB laser array with grating pitch variation of $1 \mathrm{~nm}$. The lasers with grating pitch of $341 \mathrm{~nm}$ and $355 \mathrm{~nm}$ are measured at $5{ }^{\circ} \mathrm{C}$ while other lasers are measured at $10{ }^{\circ} \mathrm{C}$. All lasers are operated CW regime with a bias current of $180 \mathrm{~mA}$. It can be found that a SMSR higher than $30 \mathrm{~dB}$ can be achieved for all of lasers. The emission wavelength shifts from $2277 \mathrm{~nm}$ 
to $2289 \mathrm{~nm}$ as the DFB grating pitch increases from $340 \mathrm{~nm}$ to $359 \mathrm{~nm} .1 \mathrm{~nm}$ change in the grating pitch results in $6 \mathrm{~nm}$ change in the emission wavelength. The laser with a grating pitch of $344 \mathrm{~nm}$ did not lase because of material defects in the III-V waveguide, which could be observed during device processing. The output power of some lasers is substantially lower than others since these lasers have material defects in the III-V taper, which introduce a large loss in the III-V/silicon SSC. The wavelength coverage of this DFB laser array overlaps with absorption bands of many gases, e.g., $\mathrm{CO}, \mathrm{CH}_{4}, \mathrm{NH}_{3}, \mathrm{HF}, \mathrm{C}_{2} \mathrm{H}_{2}$. Therefore, it can be used to detect these gases from absorption lines within this spectral range.

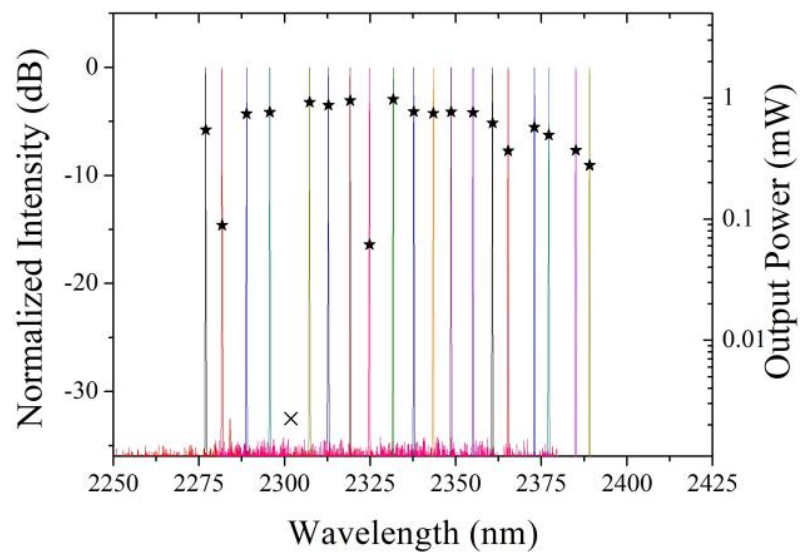

Fig. 7. Normalized emission spectra and output power (indicated by the stars) of III-V-on-silicon DFB lasers with a silicon grating pitch ranging from 340 $\mathrm{nm}$ to $359 \mathrm{~nm}$.
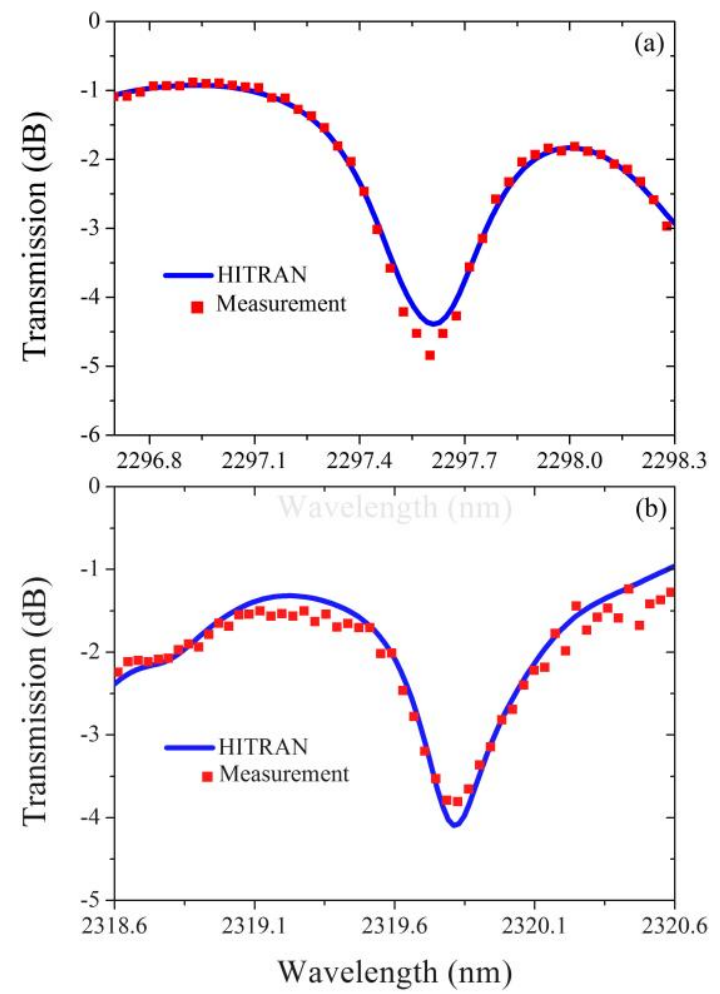

Fig. 8. TDLAS spectra of $\mathrm{NH}_{3}$ using DFB laser with grating pitch of (a) 343 $\mathrm{nm}$ at $20^{\circ} \mathrm{C}$, and (b) $347 \mathrm{~nm}$ at $15^{\circ}$.


Fig. 9. TDLAS spectra of CO using DFB laser with grating pitch of (a) 352 nm at $10{ }^{\circ} \mathrm{C}$ and (b) $358 \mathrm{~nm}$ at $5{ }^{\circ} \mathrm{C}$.

The heterogeneously integrated III-V-on-silicon DFB laser array was then used to detect $\mathrm{NH}_{3}$ and $\mathrm{CO}$ based on direct absorption spectroscopy. In the $\mathrm{NH}_{3}$ sensing setup, the light is coupled from the III-V-on-silicon chip to a single-mode fiber through the integrated on-chip grating coupler, and then coupled to a $\mathrm{NH}_{3}$ gas cell. The $5.5 \mathrm{~cm}$-long fiber-coupled gas cell contains pure $\mathrm{NH}_{3}$. DFB lasers with a grating pitch of 343 $\mathrm{nm}$ and $347 \mathrm{~nm}$ are used to detect $\mathrm{NH}_{3}$ since their wavelength tuning range overlaps with two strong absorption lines of $\mathrm{NH}_{3}$. During measurements, the DFB laser with grating pitch of 343 $\mathrm{nm}$ is operated at a heat-sink temperature of $20^{\circ} \mathrm{C}$, while the $347 \mathrm{~nm}$ device is operated at $15{ }^{\circ} \mathrm{C}$. As the bias current increases, the lasing wavelength is tuned and scanned over the absorption lines of $\mathrm{NH}_{3}$, showing a dip in the L-I curve. Based on the pre-measured current-wavelength relationship, the absorption spectra can be reconstructed. In this $\mathrm{NH}_{3}$ sensing measurements, both DFB lasers are tuned in a current step of 2 $\mathrm{mA}$, which corresponds to a wavelength step of around $36 \mathrm{pm}$. The measured absorption spectra of $\mathrm{NH}_{3}$ and the corresponding high-resolution transmission molecular absorption (HITRAN) spectra are shown in Fig. 8(a) and 8(b). Good agreement can be observed. In the CO sensing setup, the light from the III-V-onsilicon chip is coupled to a free space gas cell through a collimator. The $10 \mathrm{~cm}$-long $\mathrm{CO}$ gas cell contains pure $\mathrm{CO}$ and is AR-coated for a wavelength range around $2.35 \mu \mathrm{m}$. The DFB laser with grating pitch of $352 \mathrm{~nm}$ operated at $10{ }^{\circ} \mathrm{C}$ and that with a pitch of $358 \mathrm{~nm}$ operated at $5{ }^{\circ} \mathrm{C}$ are used. Since $\mathrm{CO}$ has much narrower absorption lines than $\mathrm{NH}_{3}$, the DFB lasers are tuned with a current step of $0.2 \mathrm{~mA}$ in the $\mathrm{CO}$ sensing measurements, which corresponds to a wavelength step of $4 \mathrm{pm}$. From the measurement results shown in Fig. 9(a) and 9(b) and 
its comparison with the HITRAN data, one can conclude that the III-V-on-silicon DFB laser array is also suitable for gases with very narrow absorption features.

\section{Combined III-V-on-silicon DFB Laser Array}

For the DFB laser array, the light emitted from different lasers should be combined to a single waveguide for applications in multi-species trace gas spectroscopy [34]. In the telecommunication wavelength range, many types of beam combiners have been developed in integrated optics for wavelength division multiplexing (WDM) optical communications, such as multimode interference (MMI) couplers and funnel combiners [35]. The silicon photonics platform can also provide a low-cost solution to realize highperformance and compact beam combiners for the short-wave infrared wavelength range. In this paper we demonstrate III-Von-silicon DFB laser arrays integrated with a beam combiner based on cascade $1 \times 2$ MMI couplers for applications in broadband spectroscopy and multi-species trace gas sensing. Figure 10(a) shows a microscope image of a four-wavelength DFB array integrated with the beam combiner. The DFB laser array has a separation of $120 \mu \mathrm{m}$ between the different devices, which share a large $p$-contact pad that is also used as a heat spreader. The beam combiner consists of two stages of $1 \times 2$ MMI couplers and S-bend SOI waveguides as shown in Fig. 10(b). The S-bend waveguides from the DFB laser to the MMI coupler have a bending radius of $50 \mu \mathrm{m}$ and those between two MMIs has a bending radius of $100 \mu \mathrm{m}$. The MMI couplers behave as 50/50 splitter/combiners and were chosen because of their small size and high tolerance to fabrication errors. The $1 \times 2$ MMI couplers have a length of $28.5 \mu \mathrm{m}$ and a width of $6.5 \mu \mathrm{m}$. A simulated field-intensity distribution of the $1 \times 2$ MMI coupler when used as a splitter is shown in Fig. 10(c). The insertion loss of the MMI coupler is lower than $0.3 \mathrm{~dB}$ in simulation.

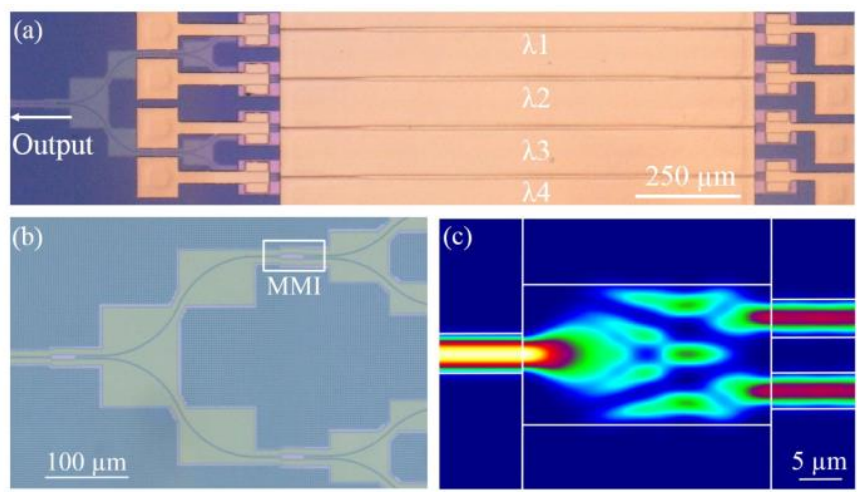

Fig. 10 (a) Microscope image of a four-wavelength III-V-on-silicon DFB laser array integrated with a cascaded MMI beam combiner; (b) zoom-in on the silicon waveguide-based beam combiner; (c) simulated intensity distribution as the light propagates through the $1 \times 2$ MMI coupler.

Figure 11(a) shows the normalized emission spectra of a beam combined four-wavelength laser array with different DFB grating pitches. All lasers are biased at $180 \mathrm{~mA}$ and operating at $15{ }^{\circ} \mathrm{C}$ during measurements. The silicon grating pitch varies from $347 \mathrm{~nm}$ to $353 \mathrm{~nm}$ with a step of $2 \mathrm{~nm}$. The lasing wavelengths of these lasers are located at $2318.9 \mathrm{~nm}, 2330.9$ $\mathrm{nm}, 2343 \mathrm{~nm}$ and $2355 \mathrm{~nm}$. A wavelength spacing of $12 \mathrm{~nm}$ is achieved. Besides varying the silicon grating pitch, the lasing wavelength of DFB lasers also can be controlled by adjusting the width of the III-V waveguide, which enables very small wavelength spacing between different channels. Figure 11(b) shows four beam combined lasers (with the same grating pitch) with III-V waveguide widths from $3.8 \mu \mathrm{m}$ to $6 \mu \mathrm{m}$ when driven at the same condition as the array shown in Fig. 11(a). The wavelength spacing in this laser array is around $1.4 \mathrm{~nm}$.
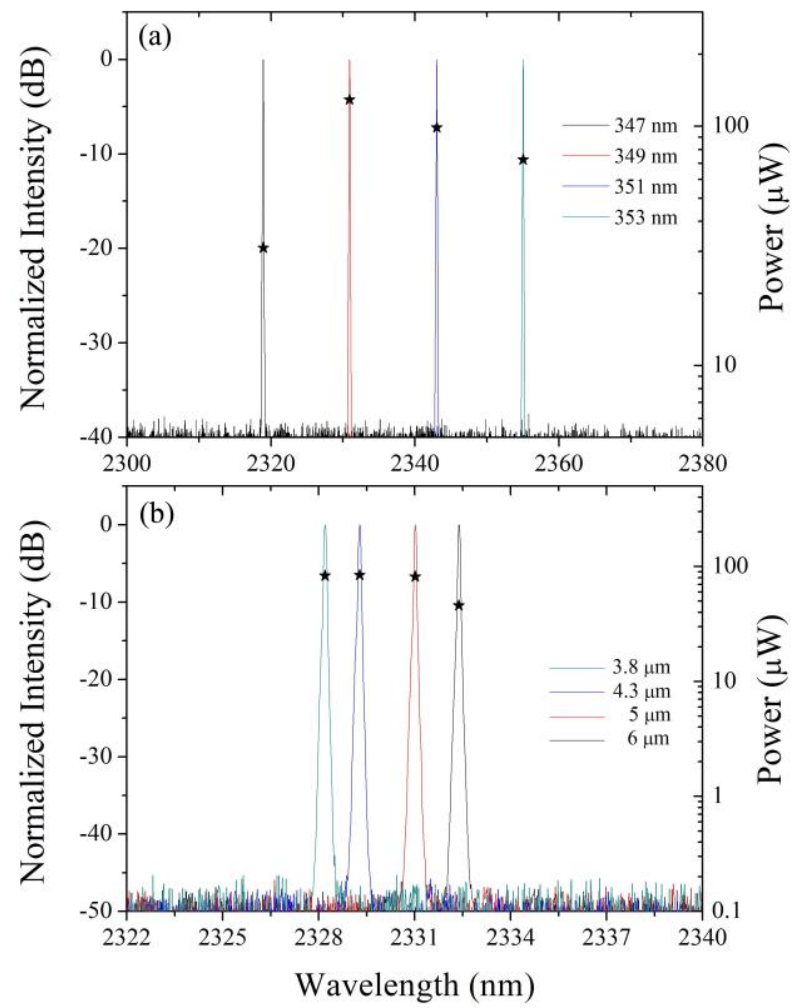

Fig. 11. Normalized emission of the beam combined III-V-on-silicon laser arrays: four DFB lasers with (a) different silicon grating pitches, (b) different III-V waveguide widths. All of lasers in each arrays are measured at the same condition. In both figures, the peak output powers are indicated by stars.

The optical loss in the beam combiners can be extracted by comparing the optical power in the common output waveguide and the waveguide connected with each device on the other side (as the DFB laser structures are symmetrical). In both III-V-onsilicon DFB laser arrays, the loss is around 6.5-7 dB for every channel. The output powers of these lasers are indicated by stars as shown in Fig. 11. This loss mainly comes from the $3 \mathrm{~dB}$ loss in every $1 \times 2$ MMI combiner. By heterogeneously integrating a III-V-on-silicon SOA on the output waveguide, this loss can be compensated. For this, we have demonstrated a heterogeneously integrated InP-based type-II SOA with peak gain of $\sim 10 \mathrm{~dB}$ and $3 \mathrm{~dB}$ bandwidth of $150 \mathrm{~nm}$ near $2.35 \mu \mathrm{m}$ wavelength. An alternative solution to reduce the loss in beam combing is replacing the beam combiners with an AWG with low-loss and flat-top passband [36]. Besides, Mach-Zehnder based optical switches also can be used as beam combiners. 


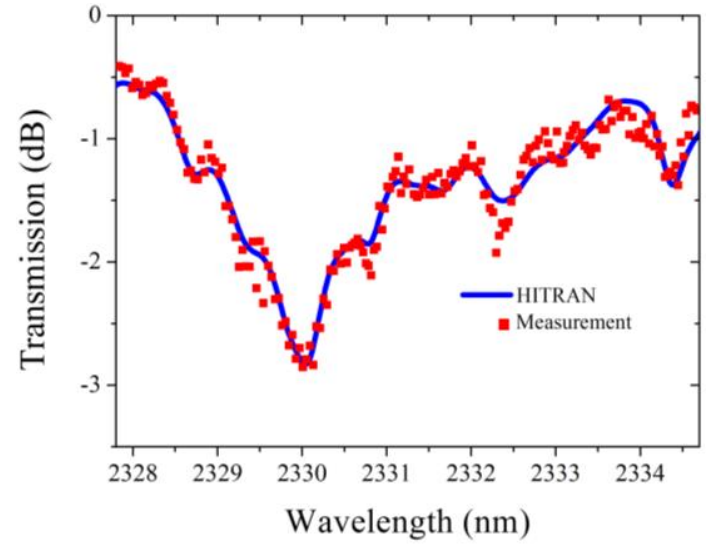

Fig. 12. TDLAS spectrum of NH3 obtained with the beam combined laser array with different III-V waveguide widths and the corresponding HITRAN spectrum.

The beam combined III-V-on-silicon DFB laser array can be used for a variety of spectroscopic applications. For example, the laser array with large wavelength spacing (e.g., the one shown in Fig. 11(a)) can be used for multi-species trace gas sensing in a broad (>120 nm) spectral range. In this array, each channel can be controlled to lase around a strong absorption line of one gas, that does not overlap with absorption lines of other gases. The laser array with small wavelength spacing can be used for mode-hop free spectroscopy over an extended wavelength range, by only adjusting the bias current of different devices without changing the heat-sink temperature to tune the lasing wavelength. Here we show its application for TDLAS of $\mathrm{NH}_{3}$ in a $>7 \mathrm{~nm}$ spectral range as shown in Fig. 12. The beam combined lasers shown in Fig. 10(b) are operated at room temperature during measurements. A good match with the HITRAN data, also shown in Fig. 12, can be observed. Using this approach, we can achieve high-resolution (sub-pm) and fast optical spectroscopy.

\section{WIDELY TUNABLE 2.3 UM III-V-ON-SILICON VERNIER LASER}

In the last section, we showed that integrating a series of DFB lasers with silicon photonics beam combiners enables widely tunable single-mode laser sources with mode hop free tuning. In this section, we summarize our recent results on another solution to realize widely tunable laser sources for spectroscopy: heterogeneously integrating short-wave infrared III-V SOAs with widely tunable silicon photonic filters [37]. The schematic of a widely tunable III-V-on-silicon laser using a silicon photonics Vernier filter to select the lasing wavelength is shown in Fig. 13. The Vernier filter and an InP-based type-II quantum well SOA are integrated in a silicon waveguide-based FabryPerot laser cavity. The epitaxial layer stack design is the same to the one used in the DFB lasers shown in the last section. The Fabry-Perot laser cavity is formed between a high-reflectivity and relatively low-reflectivity silicon DBR (DBR1 and DBR2 respectively). The light is coupled out from the laser cavity to a single mode silicon waveguide through DBR2. The Vernier filter consists of two silicon micro-ring resonators (MRRs) with slightly different radii. The radius of MRR1 and MRR2 is 49.1 $\mu \mathrm{m}$ and $44.7 \mu \mathrm{m}$, respectively. The different radii lead to different free spectral ranges (FSRs). The FSR of MRR1 and MRR2 is $5 \mathrm{~nm}$ and $5.5 \mathrm{~nm}$, respectively. Figure 14 shows the calculated transmission spectra of the two MRRs and the corresponding Vernier filter, assuming an MRR quality factor $\mathrm{Q}=2000$ and no waveguide loss. The FSR of the Vernier filter is $55 \mathrm{~nm}$. The transmission of the Vernier filter reaches a maximum when the resonant peaks of the MRRs overlap. Therefore, the lasing wavelength of the III-V-on-silicon Vernier laser is determined by the alignment of the MRR transmission spectra. In order to tune this wavelength position, a microheater is integrated on the MRRs to tune the resonant peak by the thermo-optic effect.

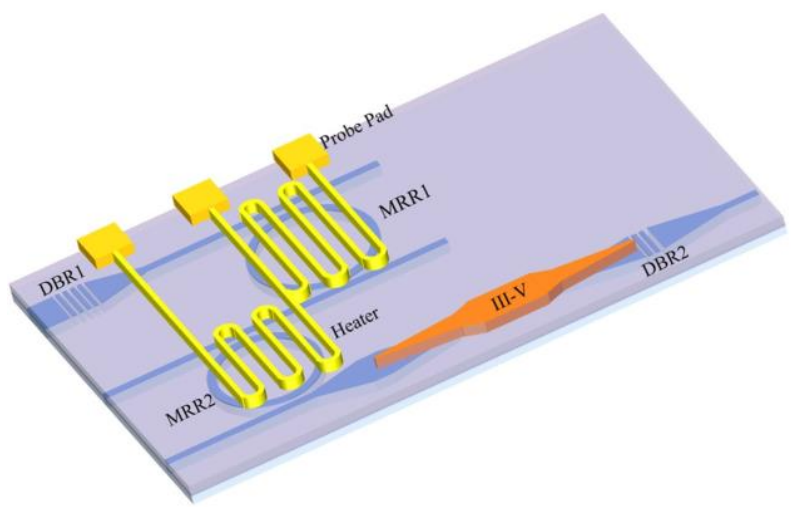

Fig. 13. Schematic of the III-V-on-silicon Vernier laser.



Fig. 14. Simulated transmission spectra of the silicon micro-ring resonators and Vernier filter.

Figure 15 shows $\mathrm{CW}$ superimposed lasing spectra and output power (indicated by the stars) of a III-V-on-silicon Vernier laser with a DBR pitch of $435 \mathrm{~nm}$ and a MRR Q-factor of 5000 at 0 ${ }^{\circ} \mathrm{C}$. A $30 \mathrm{~nm}$ wavelength tuning centered at $2.34 \mu \mathrm{m}$ is achieved by varying the electrical power dissipated in the microheater on top of MRR2. In the tuning, $29 \mathrm{~mW}$ change in the heater power dissipation leads to a $5 \mathrm{~nm}$ change in the lasing wavelength. In this device, the microheaters are deposited on a $1.8 \mu \mathrm{m}$ thick DVS-BCB passivation layer to avoid optical coupling between the silicon waveguide and heater. Because the DVS-BCB is a low thermal conductivity material, the tuning range of the laser 
is limited by the maximum electrical power that can be dissipated in the microheater and the thermal tuning efficiency. Reducing the DVS-BCB gap between the silicon waveguide and microheater can improve the thermal tuning efficiency and maximum affordable power dissipation. Therefore, we also fabricated III-V-on-silicon lasers with a $1 \mu \mathrm{m}$ DVS-BCB gap. The wavelength tuning range of this laser is improved to $50 \mathrm{~nm}$ at $5{ }^{\circ} \mathrm{C}$ (when operated in pulsed mode). However, this device did not lase in $\mathrm{CW}$ regime at $5{ }^{\circ} \mathrm{C}$ because the $1 \mu \mathrm{m}$ DVS-BCB gap between silicon waveguide and microheaters introduces optical coupling between them, resulting in a higher loss of the laser cavity.

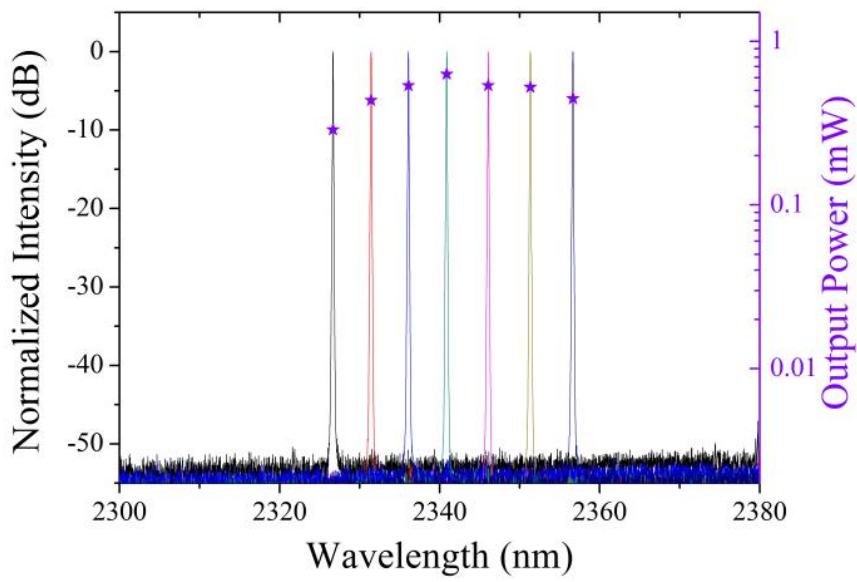

Fig. 15. Superimposed CW lasing spectra and output power of the III-V-onsilicon Vernier laser for different power dissipation in the micro-heater on MRR2.

When the Vernier laser shown in Fig. 13 is tuned by heating one of the MRRs, the tuning resolution is limited by the FSR of the unheated MRR. However, TDLAS of gases with narrow absorption lines requires laser sources that can be continuously tuned near the absorption lines. In order to precisely move the lasing wavelength close to gas absorption lines, both MRRs should be simultaneously heated to achieve a fine wavelength tuning. In this tuning method, the tuning resolution is still limited by the longitudinal mode spacing of the Fabry-Perot cavity. Then we continuously tune the lasing wavelength near the absorption lines by adjusting the bias current of the gain section. The increase of bias current results in a temperature increase in the device, which leads to an increase in the refractive index of III-V waveguide and effective laser cavity length. In this method, a continuous tuning range equal to the longitudinal mode spacing of the Fabry-Perot cavity can be achieved. Figure 16(a) show the spectral map of the fibercoupled emission spectrum of a III-V-on-silicon Vernier laser as a function of the bias current at $5{ }^{\circ} \mathrm{C}$. A continuous tuning range around $0.3 \mathrm{~nm}$ is achieved by increasing the bias current by $30 \mathrm{~mA}$. The laser keeps lasing in the $0.3 \mathrm{~nm}$ spectral range centered at $2337.4 \mathrm{~nm}$ wavelength as seen in Fig. 16 (a) since the FSR of the longitudinal modes is around $0.3 \mathrm{~nm}$. When the lasing mode is tuned too far from the overlapping resonant peak of the two MRRs, the laser will hop to another longitudinal mode closer to the transmission peak of the Vernier filter.



Fig. 16. (a) Contour map of the fiber-coupled emission spectra of a III-V-onsilicon Vernier laser as a function of the bias current; (b) spectral map after the light has passed through the $\mathrm{CO}$ gas cell.



Fig.17. (a) HITRAN absorption spectrum of $\mathrm{CO}$ in the $2315-2345 \mathrm{~nm}$ range; (b) the measured absorption spectra of three $\mathrm{CO}$ absorption lines; (c) zoom-in on the measured absorption line at $2341.2 \mathrm{~nm}$ and the corresponding HITRAN spectrum. 
We carried out a direct absorption spectroscopy measurement of $\mathrm{CO}$ to verify the performance of the III-onsilicon Vernier lasers in TDLAS. Figure 17(a) shows the HITRAN absorption spectrum of CO in the $2315 \mathrm{~nm}$ to 2345 $\mathrm{nm}$ wavelength range. Many discrete absorption lines with spacing around $2 \mathrm{~nm}$ can be seen. The strongest absorption is located around $2332 \mathrm{~nm}$ wavelength. In the TDLAS measurements, a $\mathrm{CO}$ gas cell identical to the one introduced in the last section was used. A III-V-on-silicon Vernier laser operated at $5{ }^{\circ} \mathrm{C}$ in $\mathrm{CW}$ regime is used as the laser source. In the measurements, the emission wavelength of the laser is tuned close to one of three absorption lines with different line intensity by heating both MRRs as shown in Fig. 17(b). Then high-resolution spectroscopy is achieved by continuously tuning the laser bias current. Figure 16(b) shows a contour map of the fiber-coupled laser spectra centered at $2337.4 \mathrm{~nm}$ wavelength after passing through the $\mathrm{CO}$ gas cell. Absorption dips can be seen in the spectral map as the bias current increases from $120 \mathrm{~mA}$ to $200 \mathrm{~mA}$. Based on the current-wavelength relationship, the TDLAS spectra and corresponding HITRAN spectra centered at $2341.2 \mathrm{~nm}$ are shown in Fig. 17(c). The measured absorption dip and $3 \mathrm{~dB}$ bandwidth match very well to the reference HITRAN data in all of three absorption lines. This result indicates the III-V-on-silicon Vernier laser is suitable for high-resolution TDLAS measurements.

\section{GASB/SILICON HYBRID EXTERNAL CAVITY LASERS}

In the 2-3 $\mu \mathrm{m}$ wavelength range, semiconductor lasers implemented in GaSb-based material systems show better performance than those based on InP-based materials [23]. However, the heterogeneous integration processes of GaSbbased materials are less mature than that of InP-based devices, which results in a lower process yield and laser performance for the former [24]. Here we summarize our recent work on $\mathrm{GaSb} /$ silicon external cavity lasers by butt coupling a GaSbbased gain chip with a silicon photonic IC [38]. In this method, a compact widely tunable external cavity laser can be realized by utilizing an ultra-compact silicon photonic IC and highperformance silicon photonic filters, while heterogeneous integration processes are avoided. Figure 18(a) shows the schematic of the GaSb/silicon external cavity laser. A GaSbbased superluminescent diode (SLD) is used as the gain chip. In the $2 \mathrm{~mm}$ long gain chip, a HR coating with $>95 \%$ reflectivity is applied on one facet while an AR coating with $<0.1 \%$ reflectivity is applied on the facet close to the silicon photonic IC. The AR coated facet has a tilt-angle of 5.2 degrees to avoid self-lasing in the gain chip. The light coupling between the gain chip and silicon photonic IC is realized by a silicon SSC. To match the optical mode of the light from the gain chip, a $6 \mu \mathrm{m}$ $\times 0.06 \mu \mathrm{m}$ silicon slab waveguide tilted 12 degrees is used as the facet of the silicon SSC. In order to efficiently convert the mode from the slab waveguide to that of the single mode strip waveguide $(0.7 \mu \mathrm{m} \times 0.22 \mu \mathrm{m})$, a $200 \mu \mathrm{m}$ long silicon waveguide tapered from $180 \mathrm{~nm}$ to $700 \mathrm{~nm}$ is used in the SSC. Simulations indicate that the coupling loss between the gain chip and silicon slab waveguide is around $1 \mathrm{~dB}$, and the mode conversion loss between the silicon slab waveguide and strip waveguide is also around $1 \mathrm{~dB}$. A microscope image of the interface between the gain chip and silicon photonic IC is shown in Fig. 18(b). A Fabry-Perot laser cavity is formed between the HR-coated facet of the gain chip and the silicon DBR. In the silicon photonic IC, similar to the heterogeneously integrated laser shown in Fig. 13, a Vernier filter consisting of two silicon MRRs is used to select the lasing wavelength. In order to continuously tune the lasing wavelength without changing the bias current of the gain chip, a silicon spiral waveguide is integrated in the laser cavity as a phase shifter.

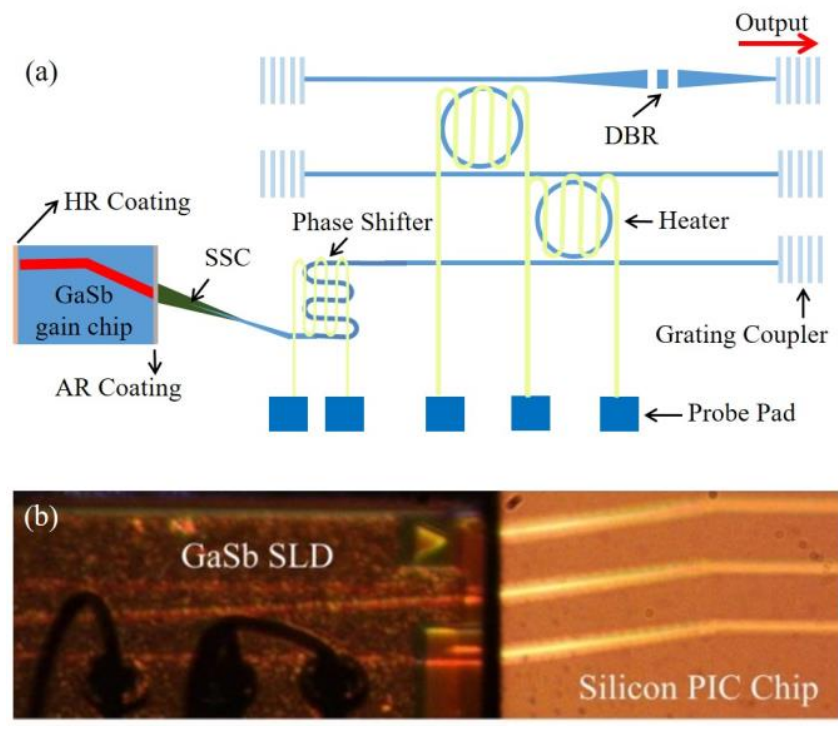

Fig. 18. (a) Schematic of the GaSb/silicon external cavity laser; (b) top-view microscope image of the butt-coupling interface.



Fig. 19. Superimposed spectra and output power of the GaSb/silicon external cavity laser when the gain chip is operated uncooled.

The wavelength tuning of the GaSb/silicon external cavity laser is also realized by adjusting the electrical power dissipated in the microheaters on the MRRs. Figure 19 shows the superimposed lasing spectra of a GaSb/silicon hybrid laser operating near $2.05 \mu \mathrm{m}$ wavelength by tuning one MRR. The GaSb-based gain chip is not cooled during measurements. A wavelength tuning range of $58 \mathrm{~nm}$ is achieved with a heater 
power consumption of $132 \mathrm{~mW}$. Every $\sim 12 \mathrm{~mW}$ electrical power change results in $6.5 \mathrm{~nm}$ wavelength shift. Over the full tuning range, a SMSR better than $52 \mathrm{~dB}$ is achieved. Similar to the heterogeneously integrated Vernier laser, a fine wavelength tuning can be achieved by simultaneously heating both MRRs and a continuous wavelength tuning can be realized by heating the phase section [38]. Under uncooled conditions, the maximum output power of the laser is around $3.8 \mathrm{~mW}$ and the threshold current density is $1 \mathrm{kA} / \mathrm{cm}^{2}$. The Q-factor the MRRs used in this Vernier laser is 13500 . When the Q-factor of the MRRs reduces, the output power will increase and the threshold current can reduce. For example, when the Q-factor of the MRR reduces to 2500 , the uncooled laser has a maximum output power of $7.5 \mathrm{~mW}$ and a threshold current density of $0.8 \mathrm{kA} / \mathrm{cm}^{2}$. However, the SMSR over the full wavelength tuning range reduces to $36 \mathrm{~dB}$ and the wavelength stability during tuning also decreases.

\section{CONClusion AND PeRsPeCtive}

Integrating III-V materials or pre-fabricated gain chips with silicon photonic ICs is very promising approach to realize widely tunable laser sources for advanced spectroscopic applications. The silicon photonics platform can provide plenty high-performance building blocks for III-V/silicon lasers, such as low-loss beam combiners, widely tunable filters and ultracompact cavities. Based on these silicon photonic components, widely tunable DFB laser arrays, Vernier lasers and external cavity lasers operating in the $2-2.5 \mu \mathrm{m}$ wavelength range have been demonstrated. These lasers are suitable for TDLAS measurement of gases in a broad spectral range. Moreover, these III-V/silicon lasers can be integrated with silicon waveguide-based probe components and III-V/silicon photodetectors to realize fully integrated on-chip spectroscopic sensors. Further improvements on the III-V/silicon laser performance are still to be made in order to achieve better performance for practical applications. For example, the output power of the heterogeneously integrated lasers at room temperature and above should be improved. This goal can be realized by optimizing the design of the III-V epitaxial layer stack and introducing better heat spreading structures. For the III-V-on-silicon Vernier laser, the DVS-BCB passivation layer can be replaced by material with higher thermal conductivity (e.g., $\mathrm{SiN}_{\mathrm{x}}$ ) to achieve a wider tuning range in $\mathrm{CW}$ mode. For the $\mathrm{GaSb} /$ silicon hybrid laser, the Vernier filter $(\mathrm{FSR}=65 \mathrm{~nm}$ ) used in the current device can be replaced by a filter with larger FSR to achieve much wider tuning range. Besides, the $\mathrm{GaSb}$ /silicon external cavity laser configuration can be used to realize laser sources in the whole $2-2.5 \mu \mathrm{m}$ and even at longer wavelengths considering the availability of the GaSb-based gain chips.

\section{ACKNOWLEDGMENT}

The authors would like to thank S. Verstuyft and M. Muneeb for metallization processing help.

\section{REFERENCES}

[1] Y. A. Vlasov, "Silicon CMOS-integrated nano-photonics for computer and data communications beyond 100G", IEEE Commun. Mag., vol. 50, no. 2, pp. s67-s72, Feb. 2012.

[2] A. Spott, E. J. Stanton, N. Volet, J. D. Peters, J. R. Meyer, and J. E. Bowers, "Heterogeneous integration for mid-infrared silicon photonics," IEEE J. Sel. Top. Quantum Electron., vol. 23, pp. 1-10, 2017.

[3] Z. Wang, A. Abbasi, U.D. Dave, A. De Groote, S. Kumari, B. Kunert, C. Merckling, M. Pantouvaki, Y. Shi, B. Tian, K. Van Gasse, J. Verbist, R. Wang, W. Xie, J. Zhang, Y. Zhu, J. Bauwelinck, X. Yin, Z. Hens, J. Van Campenhout, B. Kuyken, R. Baets, G. Morthier, D. Van Thourhout, G. Roelkens, "Novel light source integration approaches for silicon photonics," Laser \& Photonics Reviews, vol. 11, no. 4, p.1700063, 2017.

[4] S. Chen, W. Li, J. Wu, Q. Jiang, M. Tang, S. Shutts, S. N. Elliott, A. Sobiesierski, A. J. Seeds, I. Ross, P. M. Smowton, and H. Liu, "Electrically pumped continuous-wave III-V quantum dot lasers on silicon," Nat. Photonics, vol. 10, no. 5, pp. 307-311, 2016.

[5] T. Kita, R. Tang, and H. Yamada, "Narrow spectral linewidth silicon photonic wavelength tunable laser diode for digital coherent communication system," IEEE J. Sel. Top. Quantum Electron., vol. 22, no. 6, p. 1500612, 2016.

[6] S. Xiao, M. H. Khan, H. Shen, and M. Qi, "Compact silicon microring resonators with ultra-low propagation loss in the C band," Opt. Exp., vol. 15, no. 22, pp. 14467-14475, 2007.

[7] F. Horst, W. M. J. Green, S. Assefa, S. M. Shank, Y. A. Vlasov, and B. J. Offrein, "Cascaded Mach-Zehnder wavelength filters in silicon photonics for low loss and flat pass-band WDM (de-)multiplexing," Opt. Exp., vol. 21, no. 10, pp. 11652-11658, 2013.

[8] A. Li, W. Bogaerts, "Experimental Demonstration of a Single Silicon Ring Resonator with an ultra wide FSR and tuning range," Opt. Lett., vol. 42, no. 23, pp.4986-4989, 2017.

[9] Z. Wang, K. Van Gasse, V. Moskalenko, S. Latkowski, E. Bente, B. Kuyken, and G. Roelkens, "A III-V-on-Si ultra-dense comb laser," Light Sci. Appl., vol. 6, p. e16260, 2017.

[10] T. Kita, R. Tang, and H. Yamada, "Compact silicon photonic wavelengthtunable laser diode with ultra-wide wavelength tuning range," Appl. Phys. Lett., vol. 106, no. 11, p. 111104, 2015.

[11] L. Tombez, E. J. Zhang, J. S. Orcutt, S. Kamlapurkar, and W. M. J. Green, "Methane absorption spectroscopy on a silicon photonic chip," Optica, vol. 4, no. 11, pp. 1322-1325, Nov. 2017.

[12] E.M.P. Ryckeboer, J. Vierendeels, A. Lee, S. Werquin, P. Bienstman, R. Baets, "Measurement of small molecule diffusion with an optofluidic silicon chip," Lab on a Chip, vol. 13, no. 22, pp.4392 - 4399, 2013.

[13] J. T. Robinson, L. Chen, and M. Lipson, "On-chip gas detection in silicon optical microcavities,” Opt. Exp., vol. 16, no. 6, pp. 4296-4301, 2008.

[14] F. Dell'Olio and V. M. Passaro, "Optical sensing by optimized silicon slot waveguides," Opt. Exp., vol. 15, no. 8, pp. 4977-4993, 2007.

[15] M. Lee and P. M. Fauchet, "Two-dimensional silicon photonic crystal based biosensing platform for protein detection," Opt. Exp., vol. 15, no. 8, pp. 4530-4535, 2007.

[16] L. S. Rothman, I. E. Gordon, Y. Babikov, A. Barbe, D. Chris Benner, P. F. Bernath, M. Birk, L. Bizzocchi, V. Boudon, L. R. Brown, A. Campargue, K. Chance, E. A. Cohen, L. H. Coudert, V. M. Devi, B. J. Drouin, A. Fayt, J.-M. Flaud, R. R. Gamache, J. J. Harrison, J.-M. Hartmann, C. Hill, J. T. Hodges, D. Jacquemart, A. Jolly, J. Lamouroux, R. J. Le Roy, G. Li, D. A. Long, O. M. Lyulin, C. J. Mackie, S. T. Massie, S. Mikhailenko, H. S. P. Müller, O. V. Naumenko, A. V. Nikitin, J. Orphal, V. Perevalov, A. Perrin, E. R. Polovtseva, C. Richard, M. A. H. Smith, E. Starikova, K. Sung, S. Tashkun, J. Tennyson, G. C. Toon, V. G. Tyuterev, and G. Wagner, "The HITRAN2012 molecular spectroscopic database," J. Quant. Spectrosc. Radiat. Transf., vol., 130, pp. 4-50, 2013.

[17] S. Forouhar, R. M. Briggs, C. Frez, K. J. Franz, and A. Ksendzov, "Highpower laterally coupled distributed-feedback GaSb-based diode lasers at $2 \mu \mathrm{m}$ wavelength," Appl. Phys. Lett., vol. 100, no. 3, pp. 031107, 2012.

[18] D. Sanchez, L. Cerutti, and E. Tournié, "Single-Mode Monolithic GaSb Vertical-Cavity Surface-Emitting Laser", Opt. Exp., vol. 20, no. 14, pp. 15540-15546, 2012.

[19] F. Xu, S. Luo, F. Gao, H.-M. Ji, Z.-R. Lv, X.-G. Yang, and T. Yang, "2004-nm Ridge-Waveguide Distributed Feedback Lasers with InGaAs Multi-Quantum Wells," IEEE Photon. Tech. Lett., vol. 28, no. 20, pp. 2257-2260, 2016.

[20] S. Sprengel, A. Andrejew, F. Federer, G. K. Veerabathran, G. Boehm, and M.-C. Amann, "Continuous wave vertical cavity surface emitting lasers 
at $2.5 \mu \mathrm{m}$ with InP-based type-II quantum wells," Appl. Phys. Lett., vol. 106, no. 15, pp. 151102, 2015.

[21] N. V. Alexeeva and M. A. Arnold, "Near-infrared microspectroscopic analysis of rat skin tissue heterogeneity in relation to noninvasive glucose sensing," J. Diabetes Sci. Technol., vol. 3, no.2, pp. 219-232, 2009.

[22] K. Vizbaras, E. Dvinelis, I. Šimonyte, A. Trinkūnas, M. Greibus, R. Songaila, T. Žukauskas, M. Kaušylas, and A. Vizbaras, "High power continuous-wave GaSb-based superluminescent diodes as gain chips for widely tunable laser spectroscopy in the $1.95-2.45 \mu \mathrm{m}$ wavelength range," Appl. Phys. Lett., vol. 107, no.1, pp. 011103, 2015.

[23] A. Bauer, K. Rner, T. Lehnhardt, M. Kamp, S. Hfling, L. Worschech, and A. Forchel, "Mid-infrared semiconductor heterostructure lasers for gas sensing applications," Semicond. Sci. Technol., 26(1), 4032 (2011).

[24] G. Roelkens, U.D. Dave, A. Gassenq, N. Hattasan, C. Hu, B. Kuyken, F. Leo, A. Malik, M. Muneeb, E.M.P. Ryckeboer, D. Sanchez, S. Uvin, R. Wang, Z. Hens, R. Baets, Y. Shimura, F. Gencarelli, B. Vincent, R. Loo, J. Van Campenhout, L. Cerutti, J.B. Rodriguez, E. Tournie, X. Chen, M. Nedeljkovic, "Silicon-based photonic integration beyond the telecommunication wavelength range," IEEE J. Sel. Top. Quantum Electron., vol. 20, no. 4, pp.8201511, 2014.

[25] A. Spott, M. Davenport, J. Peters, J. Bovington, M. J. R. Heck, E. J. Stanton, I. Vurgaftman, J. Meyer, and J. Bowers, "Heterogeneously integrated $2.0 \mu \mathrm{m} \mathrm{CW}$ hybrid silicon lasers at room temperature," Opt. Lett., vol. 40, no. 7, pp. 1480-1483, 2015.

[26] G. Boehm, M. Grau, O. Dier, K. Windhorn, E. Roenneberg, J. Rosskopf, R. Shau, R. Meyer, M. Ortsiefer, and M. C. Amann, "Growth of InAscontaining quantum wells for InP-based VCSELs emitting at $2.3 \mu \mathrm{m}$," $J$. Cryst. Growth, vol. 301-302, pp. 941-944, 2007.

[27] S. Sprengel, C. Grasse, P. Wiecha, A. Andrejew, T. Gruendl, G. Boehm, R. Meyer, and M.-C. Amann, "InP-Based Type-II Quantum-Well Lasers and LEDs," IEEE J. Sel. Top. Quantum Electron., vol. 19, no. 4, pp. $1900909,2013$.

[28] R. Wang, S. Sprengel, G. Boehm, M. Muneeb, R. Baets, M. C. Amann, and G. Roelkens, " $2.3 \mu \mathrm{m}$ range InP-based type-II quantum well FabryPerot lasers heterogeneously integrated on a silicon photonic integrated circuit," Opt. Exp., vol. 24, no. 18, pp. 21081-21089, 2016.

[29] S. Keyvaninia, M. Muneeb, S. Stanković, P. J. Van Veldhoven, D. Van Thourhout, and G. Roelkens, "Ultra-thin DVS-BCB adhesive bonding of III-V wafers, dies and multiple dies to a patterned silicon-on-insulator substrate," Opt. Mater. Exp., vol. 3, no. 1, pp. 35-46, 2013.

[30] R. Wang, M. Muneeb, S. Sprengel, G. Boehm, A. Malik, R. Baets, M.-C. Amann, and G. Roelkens, "III-V-on-silicon 2- $\mu \mathrm{m}$-wavelength-range wavelength demultiplexers with heterogeneously integrated InP-based type-II photodetectors," Opt. Exp., vol. 24, no. 8, pp. 8480-8490, 2016.

[31] S. Sprengel, G. Veerabathran, A. Köninger, F. Federer, G. Boehm, and M.-C.Amann, "InP-based type-II heterostructure lasers for $2.5 \mu \mathrm{m}$ working $\mathrm{CW}$ at room temperature and above," in IEEE International Semiconductor Laser Conference, paper MC.05, 2014.

[32] R. Wang, S. Sprengel, A. Malik, A. Vasiliev, G. Boehm, R. Baets, M.-C. Amann, and G. Roelkens, "Heterogeneously integrated III-V-on-silicon $2.3 \mathrm{x} \mu \mathrm{m}$ distributed feedback lasers based on a type-II active region," Appl. Phys. Lett., vol., 109, pp. 221111, 2016.

[33] R. Wang, S. Sprengel, G. Boehm, R. Baets, M.-C. Amann, and G. Roelkens, "Broad wavelength coverage $2.3 \mu \mathrm{m}$ III-V-on-silicon DFB laser array," Optica, vol. 4, no. 8, pp. 972-975, 2017.

[34] L. Bizet, R. Vallon, B. Parvitte, M. Brun, G. Maisons, M. Carras, and V. Zeninari, "Multi-gas sensing with quantum cascade laser array in the midinfrared region," Appl. Phys. B, vol. 123, pp. 145, 2017.

[35] H. Ishii, K. Kasaya, H. Oohashi, Y. Shibata, H. Yasaka, and K. Okamoto, "Widely wavelength-tunable DFB laser array integrated with funnel combiner," IEEE J. Quantum Electron., vol. 13, no. 5, pp. 1089-1094, 2007.

[36] S. Pathak, M. Vanslembrouck, P. Dumon, D. Van Thourhout, and W. Bogaerts, "Optimized silicon AWG with flattened spectral response using an MMI aperture," J. Lightwave Technol., vol. 31, no. 1, pp. 87-93, 2013.

[37] R. Wang, S. Sprengel, A. Vasiliev, G. Boehm, J. V. Campenhout, G. Lepage, P. Verheyen, R. Baets, M.-C. Amann, and G. Roelkens, "Widely tunable $2.3 \mu \mathrm{m}$ III-V-on-silicon Vernier lasers for broadband spectroscopic sensing," Photonics Research, vol.6, no.9, pp. 858-866, 2018.

[38] R. Wang, A. Malik, I. Šimonytè, A. Vizbaras, K. Vizbaras, and G. Roelkens, "Compact $\mathrm{GaSb} /$ silicon-on-insulator $2.0 \times \mu \mathrm{m}$ widely tunable external cavity lasers," Opt. Exp., vol. 24, no.25 , pp. 28977-28986, 2016. 